\title{
O protagonismo do enfermeiro no ambiente escolar: a educação em saúde pode
}

\section{salvar vidas}

The nurse's role in the school environment: health education can save lives

El papel de las enfermeras en el entorno escolar: la educación sanitaria puede salvar vidas

Recebido: 14/12/2021 | Revisado: 19/12/2021 | Aceito: 25/12/2021 | Publicado: 05/01/2022

\author{
Junior de Jesus Guimarães \\ ORCID: https://orcid.org/0000-0002-4736-6603 \\ Universidade Tiradentes, Brasil \\ E-mail: juniorguimaraes123@ hotmail.com \\ Jean David Alves da Silva \\ ORCID: https://orcid.org/0000-0003-2669-9529 \\ Universidade Tiradentes, Brasil \\ E-mail: jeandavid1@ hotmail.com \\ Derijulie Siqueira de Sousa \\ ORCID: https://orcid.org/0000-0001-7209-1034 \\ Universidade Tiradentes, Brasil \\ E-mail: Deriartur@gmail.com \\ Carine Santana Ferreira Marques \\ ORCID: https://orcid.org/0000-0002-5729-915X \\ Universidade Tiradentes, Brasil \\ E-mail: carine.santaferreira@gmail.com \\ Thialla Andrade Carvalho \\ ORCID: https://orcid.org/0000-0002-3301-5060 \\ Instituto Federal de Sergipe, Brasil \\ E-mail: Thialla.carvalho@ifs.edu.b
}

\begin{abstract}
Resumo
O objetivo do estudo é descrever as ações dos profissionais e estudantes da saúde no ambiente escolar, priorizando o enfermeiro como protagonista de educação em saúde de forma preventiva com ênfase nos primeiros socorros. Tratase de uma revisão integrativa, na qual foi elaborado o referencial teórico através de pesquisa nas bases de dados eletrônicos: Biblioteca Virtual em Saúde (BVS) e nas seguintes bases de dados: National Library of Medicine (PubMed), Scientific Electronic Library Online (SciELO) e revistas científica eletrônica. Nos períodos de 2015-2021. Foi possível evidenciar como a atuação da enfermagem no âmbito escolar para a promoção do conhecimento em primeiros socorros é vital para evitar desfechos alarmantes em situações de risco iminente. Muitas vezes o público leigo é o primeiro a evidenciar esses casos, nesse ínterim a formação desse público em primeiros socorros desde a fase escolar é algo essencial para que essa criança ao se tornar adulto conheça as condutas básicas de suporte básico a vida e consiga prestar uma assistência mais qualificada. Após a análise de todos os fatores que compõem esse estudo, podemos concluir que a presença de um profissional de saúde, em particular o enfermeiro dentro do ambiente escolar como educador e promotor de saúde, a escola por sua vez, é responsável pela formação e construção dos cidadãos da nossa sociedade, com isso faz-se necessário a introdução de um plano de treinamento de suporte básico de vida, influenciar na migração da cultura curativa para uma cultura mais preventiva.
\end{abstract}

Palavras-chave: Primeiros socorros; Acidentes; Escolas.

\begin{abstract}
The objective of this study is to describe the actions of health professionals and students in the school environment, prioritizing the nurse as a protagonist of health education in a preventive way with emphasis on first aid. This is an integrative review, in which the theoretical framework was developed through research in electronic databases: Virtual Health Library (VHL) and the following databases: National Library of Medicine (PubMed), Scientific Electronic Library Online (SciELO) and electronic scientific journals. In the periods 2015-2021. It was possible to show how the performance of nursing in the school environment for the promotion of first aid knowledge is vital to avoid alarming outcomes in situations of imminent risk. Many times, the lay public is the first to show these cases, meanwhile, the education of this public in first aid since the school phase is essential so that this child, when becoming an adult, knows the basic conducts of basic life support and is able to provide a more qualified assistance. After analyzing all the factors that make up this study, we can conclude that the presence of a health professional, particularly a nurse, within the school environment as an educator and promoter of health, the school in turn, is responsible for training and building the citizens of our society, thus making it necessary to introduce a basic life
\end{abstract}


support training plan, to influence the migration of curative culture to a more preventive culture. Keywords: First aid; Accidents; Schools.

\section{Resumen}

El objetivo del estudio es describir la actuación de los profesionales de la salud y de los alumnos en el ámbito escolar, priorizando a la enfermera como protagonista de la educación sanitaria de forma preventiva con énfasis en los primeros auxilios. Se trata de una revisión integradora, en la que el marco teórico se desarrolló a través de la investigación en bases de datos electrónicas: Biblioteca Virtual de Salud (BVS) y las siguientes bases de datos: National Library of Medicine (PubMed), Scientific Electronic Library Online (SciELO) y revistas científicas electrónicas. En los períodos 2015-2021. Se pudo evidenciar cómo la actuación de la enfermería en el ámbito escolar para la promoción de conocimientos en primeros auxilios es vital para evitar resultados alarmantes en situaciones de riesgo inminente. Muchas veces, el público lego es el primero en mostrar estos casos, mientras tanto, la formación de este público en primeros auxilios desde la fase escolar es esencial para que este niño, al convertirse en adulto, conozca las conductas básicas de soporte vital básico y sea capaz de prestar una asistencia más cualificada. Después del análisis de todos los factores que componen este estudio, podemos concluir que la presencia de un profesional de la salud, en particular la enfermera dentro del ámbito escolar como educador y promotor de la salud, la escuela a su vez, es responsable de la formación y construcción de los ciudadanos de nuestra sociedad, por lo que es necesario introducir un plan de formación sobre el soporte vital básico, para influir en la migración de la cultura curativa a una cultura más preventiva.

Palabras clave: Primeros auxilios; Accidentes; Escuelas.

\section{Introdução}

No exercício da enfermagem o enfermeiro atua na coordenação e no incentivo das práticas que envolvem a promoção, prevenção e tratamento em situações de saúde/doença (Ordem dos enfermeiros, 2019). Para que sua prática seja efetiva, independentemente do local de atuação, é necessário amplo conhecimento científico, construção e fortalecimento de vínculo com a comunidade e a realização autônoma de intervenções em saúde, seja na prestação de cuidados, na gestão ou como promovedor de educação em saúde.

Atinando que o ambiente escolar contribui para a formação do cidadão, e considerando que a criança permanece parte considerável do seu dia na escola, percebemos que existe a grande necessidade de trabalhar temáticas voltadas à saúde humana como forma de prevenir acidentes e agravos e promover saúde, com ênfase em situações de acidentes, seja por queda, engasgo ou intoxicação. (Lima et al., 2016).

Acidente é compreendido como o acontecimento não intencional, evitável e gerador de danos físicos e/ou emocionais no âmbito doméstico ou nos outros ambientes sociais. Trata-se de eventos não esperados e não planejados, que mostram uma disfunção do meio onde ocorre (Moura, et al., 2018).

Os acidentes na infância configuram um sério problema para o sistema de saúde no mundo, sendo responsáveis por um grande número de atendimento nas urgências hospitalares. No Brasil, durante o ano de 2015, essas eventualidades ocasionaram um total de 72.611 mil óbitos de crianças, seja por agravos não intencionais, trânsito, afogamento, queimaduras, quedas, asfixia e intoxicação, Ocasionando mais vítimas que as principais doenças que acometem crianças e jovens, gerando cerca de 117 mil hospitalizações na rede pública em 2017 (SPSP, 2017).

Estudos indicam que os esportes escolares nos momentos de recreação dos alunos, são uma das principais causas de acidentes nas escolas, que podem advir facilmente no dia a dia da criança (Grimaldi et al., 2020).

Nessa perspectiva observa-se a importância da capacitação em primeiros socorros de professores e funcionários. E, após um acidente envolvendo um garoto de 10 anos durante uma excursão escolar, foi criada a Lei 13.722 de 2018 , denominada de Lei Lucas. Essa lei torna obrigatória a capacitação em primeiros socorros de professores e funcionários de estabelecimentos escolares públicos e privados (BRASIL, 2018).

A conduta de qualidade durante um acidente é de extrema importância, principalmente nos primeiros minutos da situação ocorrida. A não assistência ou a assistência inadequada pode levar ao agravamento da situação ou ao óbito. Vale 
ressaltar também que a aspiração de corpo estranho matou 806 crianças em 2015, ocupando o $10^{\circ}$ lugar em causas de óbitos de crianças menores de cinco anos (Grimaldi et al., 2020).

Nos ambientes escolares os estudantes atuam de forma eficiente como multiplicadores de conhecimento, o que revela a importância da capacitação destes. Com isso, eles poderão atuar transferindo a cultura de socorrer de forma correta entre colegas e familiares. Os primeiros socorros são mecanismos incipientes de emergência de menor complexidade, objetivando preservar a vida e evitar prejuízos maiores até que o indivíduo receba atendimento especializado. Essa assistência inicial acontece de forma imediata ao indivíduo com agravo à saúde (Alba, 2015).

Nesse contexto, as escolas são locais de promoção da saúde e prevenção de doenças é o local onde a criança passa boa parte do tempo e é exposta a diversos riscos. Portanto, esse estudo tem como objetivo descrever as ações dos profissionais e estudantes da saúde no ambiente escolar, priorizando o enfermeiro como protagonista de educação em saúde de forma preventiva com ênfase nos primeiros socorros.

\section{Metodologia}

\subsection{Delineamento do estudo}

A revisão integrativa é um método que analisa amplamente a literatura e sintetiza os estudos existentes de uma determinada temática. Além disso, executa levantamentos importantes sobre falhas de conhecimento e necessidades de novos estudos (MENDES, K.D.S et. al. 2008). Para a elaboração desse tipo de estudo é preciso seguir alguns passos, como é demonstrado na Figura 1.

Figura 1 - Fases da revisão Integrativa.

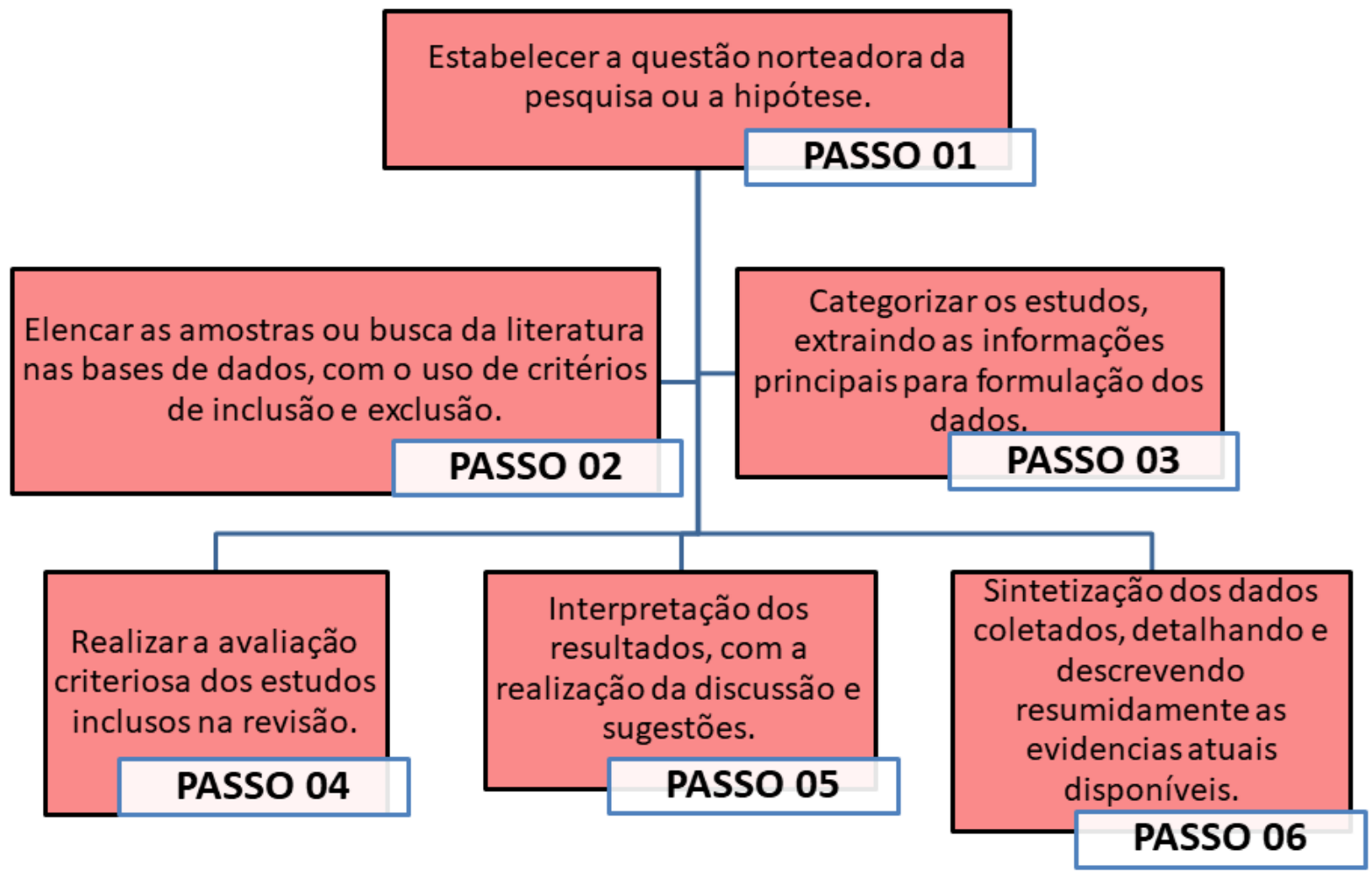

Fonte: Mendes et al. (2008). 


\subsection{Local de pesquisa/base de dados}

Para enumeração dos artigos na literatura, foi executado uma pesquisa de forma eletrônica, a partir de fontes secundárias, utilizando busca avançada na Biblioteca Virtual em Saúde (BVS) e nas seguintes bases de dados: National Library of Medicine (PubMed), Scientific Electronic Library Online (SciELO) e revistas científica eletrônica.

\subsection{Amostra}

Para a composição dessa pesquisa foram utilizados os Descritores em Ciência da Saúde (DeCS): Primeiros Socorros, Acidentes, Escolas, juntamente com os operadores booleanos or/and.

\subsection{Critérios de Inclusão e exclusão}

Foram incluídos artigos que contemplassem a questão norteadora, publicados em português, inglês e espanhol, que fossem de acesso on-line, gratuito e com recorte temporal de 2015 a 2021.

Os critérios de exclusão foram: Artigos duplicados nas bases de dados, que não contemplavam a temática e artigos com data inferior a 2015 .

Com a questão norteadora: Qual é a atuação do enfermeiro e profissionais de saúde frente a educação em saúde na prevenção de acidentes no ambiente escolar?

\subsection{Análise dos Dados}

A síntese das informações foram selecionadas dos artigos, viabilizando a descrição e análise dos achados que contemplem a temática, esquematizando e avaliando os estudos científicos alcançados.

Os dados foram tabelados por meio do Microsoft Excel, realizado fichamento dos artigos com as principais ideias dos autores para direcionar a leitura e produção eficiente.

\subsection{Aspectos éticos da pesquisa}

Para a elaboração desse estudo, foi levado em consideração todas as convicções éticas e autorais do conteúdo pesquisado, certificando a referenciação dos autores conforme instituído pela Associação Brasileira de Normas Técnicas (ABNT). Para a realização dessa pesquisa não houve a necessidade de submissão ao Comitê de Ética e Pesquisa da Universidade Tiradentes (CEP-UNIT) exercendo todos os princípios da resolução 466/16.

\section{Resultados}

No presente estudo, foram avaliados 27 artigos sendo delimitados de acordo com os critérios de inclusão, após reavaliação foram excluídos 05 artigos por não serem de acesso gratuito. No qual, totalizou-se, então, 22 artigos selecionados que possibilitaram a resposta à questão norteadora e que foram disponibilizados em concordância com o recorte temporal estipulado (2015-2021). Sendo 05 artigos da Biblioteca Virtual em Saúde (BVS); 06 artigos da Scientific Electronic Library Online (Scielo); 03 artigos da PUBMed e 08 artigos encontrados de forma livre em revistas científicas eletrônicas. 
Quadro 1: Distribuição dos artigos encontrados.

\begin{tabular}{|c|c|c|c|}
\hline Base de dados & Artigos encontrados & Artigos incluídos & Artigos excluídos \\
\hline BVS & 5 & 5 & 0 \\
\hline SCIELO & 7 & 6 & 1 \\
\hline PUBMED & 3 & 3 & 4 \\
\hline REVISTAS & 12 & 8 & 5 \\
\hline TOTAL & 27 & 22 & 0 \\
\hline
\end{tabular}

Fonte: Autores.

Quadro 2: Seleção dos artigos de acordo com o autor(es), ano, país, objetivos, tipo de estudo e síntese dos principais resultados.

\begin{tabular}{|c|c|c|c|c|}
\hline $\operatorname{AUTOR}(E S) /$ ANO & País & Objetivo & $\begin{array}{ll}\text { Tipo } & \text { de } \\
\text { estudo } & \end{array}$ & PRINCIPAIS RESULTADOS \\
\hline $\begin{array}{l}\text { CORNACINE, A.C. et al. } \\
\text { / } 2018\end{array}$ & Brasil & $\begin{array}{l}\text { O objetivo deste estudo foi analisar } \\
\text { a importância do atendimento } \\
\text { emergencial, seja por socorristas } \\
\text { quanto profissionais de saúde, como } \\
\text { o farmacêutico e a relevância de } \\
\text { treinamentos, mesmo que básicos, } \\
\text { de primeiros socorros para a } \\
\text { população em geral. }\end{array}$ & $\begin{array}{l}\text { Revisão de } \\
\text { literatura }\end{array}$ & $\begin{array}{l}\text { Os resultados desse estudo } \\
\text { demonstraram a importância do } \\
\text { treinamento em primeiros socorros } \\
\text { tanto para profissionais de saúde quanto } \\
\text { para a população em geral que se } \\
\text { apresentam leigos no assunto. }\end{array}$ \\
\hline $\begin{array}{l}\text { SANTANA, M.M.R. et.al } \\
\text { / } 2020\end{array}$ & Brasil & $\begin{array}{l}\text { Comparar o conhecimento de } \\
\text { escolares do ensino básico sobre } \\
\text { primeiros socorros antes e após uma } \\
\text { intervenção educativa sobre o tema. }\end{array}$ & $\begin{array}{l}\text { Estudo quase- } \\
\text { experimental }\end{array}$ & $\begin{array}{l}\text { Demonstrou a emergente necessidade } \\
\text { de implementar disciplinas que } \\
\text { abordam conteúdos de primeiros } \\
\text { socorros no currículo do ensino escolar. }\end{array}$ \\
\hline $\begin{array}{l}\text { NETO, N.M.G. et.al / } \\
2018\end{array}$ & Brasil & $\begin{array}{l}\text { Desvendar as vivências de } \\
\text { professores do ensino infantil e } \\
\text { fundamental sobre primeiros } \\
\text { socorros na escola. }\end{array}$ & $\begin{array}{l}\text { Estudo } \\
\text { descritivo/ } \\
\text { Qualitativo. }\end{array}$ & $\begin{array}{l}\text { Nos resultados foram demonstrados que } \\
\text { os professores, apesar de por vezes } \\
\text { terem o conhecimento necessário para } \\
\text { abordar o indivíduo em situação de } \\
\text { risco, não apresentam a estrutura } \\
\text { psicológica para agir e comunicar o } \\
\text { familiar da ocorrência, o que torna } \\
\text { imperativo trabalhar a tríade saúde, } \\
\text { educação e família, }\end{array}$ \\
\hline MARTIN, A.R. / 2015 & Espanha & $\begin{array}{l}\text { Avaliar o aumento do nível de } \\
\text { conhecimento sobre primeiros } \\
\text { socorros em professores, após uma } \\
\text { intervenção educativa. }\end{array}$ & $\begin{array}{l}\text { Estudo } \\
\text { campo }\end{array}$ & $\begin{array}{ll}\text { Os resultados apontaram que, antes da } \\
\text { intervenção educacional, os professores } \\
\text { apresentavam deficiência no } \\
\text { conhecimento dos primeiros socorros. } \\
\text { Algo suprido posteriormente a } \\
\text { intervenção }\end{array}$ \\
\hline
\end{tabular}




\begin{tabular}{|c|c|c|c|c|}
\hline $\begin{array}{l}\text { SILVA, L.G.S. et.al / } \\
2017\end{array}$ & Brasil & $\begin{array}{l}\text { Descrever uma ação educativa com } \\
\text { professores do ensino primário e } \\
\text { identificar possíveis situações de } \\
\text { risco para acidentes }\end{array}$ & $\begin{array}{l}\text { Relato de } \\
\text { experiência }\end{array}$ & $\begin{array}{l}\text { O resultado da avaliação pedagógica foi } \\
\text { promissor. Os docentes conseguiram } \\
\text { usar dos debates compartilhados no } \\
\text { encontro e descreveram suas atuações } \\
\text { de forma responsável e cuidadosa. }\end{array}$ \\
\hline SILVA, D.P. et. al / 2018 & Brasil & $\begin{array}{lll}\text { Avaliar o impacto do ensino de } \\
\text { primeiros } & \text { socorros } & \text { no } \\
\text { conhecimento e } & \text { e habilidade } & \text { de } \\
\text { professores. } & & \end{array}$ & $\begin{array}{l}\text { Revisão de } \\
\text { literatura }\end{array}$ & $\begin{array}{l}\text { Os resultados obtidos neste artigo } \\
\text { foram que os testes pré-intervenção, de } \\
\text { todos os } \\
\text { profissionais avaliados, revelaram } \\
\text { resultados inferiores aos testes pós- } \\
\text { intervenção, que por sua vez } \\
\text { apresentaram melhora significativa na } \\
\text { média de respostas corretas, quando } \\
\text { avaliados os conhecimentos ou } \\
\text { habilidades em primeiros socorros. }\end{array}$ \\
\hline BRITO, J.G. et. al / 2018 & Brasil & $\begin{array}{l}\text { Analisar o efeito de uma } \\
\text { capacitação no conhecimento da } \\
\text { equipe multidisciplinar de escolas } \\
\text { de ensino especializado sobre } \\
\text { primeiros socorros diante de } \\
\text { acidentes escolares. }\end{array}$ & $\begin{array}{l}\text { Estudo quase } \\
\text { experimental }\end{array}$ & $\begin{array}{l}\text { Sugere-se maior atuação do enfermeiro } \\
\text { no ambiente escolar, uma vez que seu } \\
\text { papel é fundamental para promoção da } \\
\text { saúde e prevenção de agravos, } \\
\text { prevenção de acidentes e primeiros } \\
\text { socorros. }\end{array}$ \\
\hline $\begin{array}{l}\text { GRIMALDI, M. R. M. et. } \\
\text { al / } 2020\end{array}$ & Brasil & $\begin{array}{l}\text { Implementar estratégia educativa } \\
\text { sobre noções básicas de primeiros } \\
\text { socorros com estudantes de escola } \\
\text { pública e particular e verificar o } \\
\text { conhecimento destes antes e após a } \\
\text { intervenção educativa. }\end{array}$ & $\begin{array}{l}\text { Estudo } \\
\text { exploratório }\end{array}$ & $\begin{array}{l}\text { Foi realizado um teste pré e pós } \\
\text { intervenção educativa, o resultado } \\
\text { obtido foi um avanço no conhecimento } \\
\text { sobre primeiros socorros pós } \\
\text { intervenção. }\end{array}$ \\
\hline $\begin{array}{l}\text { LEITE, H.S.L. et. al / } \\
2018\end{array}$ & Brasil & $\begin{array}{l}\text { O estudo teve como objetivo avaliar } \\
\text { o nível de conhecimento dos } \\
\text { componentes da gestão educacional } \\
\text { sobre noções básicas de primeiros } \\
\text { socorros. }\end{array}$ & $\begin{array}{l}\text { Estudo } \\
\text { exploratório/d } \\
\text { escritivo com } \\
\text { caráter e } \\
\text { abordagem } \\
\text { quantitativa. }\end{array}$ & $\begin{array}{l}\text { Esse estudo demonstrou a importância } \\
\text { de realizar a capacitação dos } \\
\text { profissionais que integram o cenário } \\
\text { escolar, no sentido de conhecer as } \\
\text { principais intervenções de primeiros } \\
\text { socorros, para serem utilizados quando } \\
\text { necessário, já que esses não } \\
\text { demonstram um conhecimento efetivo } \\
\text { para que possam agir nessas situações. }\end{array}$ \\
\hline BONÉ, M. et. al / 2020 & Portugal & $\begin{array}{l}\text { Este trabalho objetiva conhecer } \\
\text { fatores facilitadores e barreiras à } \\
\text { aprendizagem de SBV e } \\
\text { competências reveladas por alunos } \\
\text { sujeitos à aprendizagem e treino de } \\
\text { SBV, em países europeus, com base } \\
\text { na revisão da literatura disponível. }\end{array}$ & $\begin{array}{l}\text { Revisão de } \\
\text { literatura }\end{array}$ & $\begin{array}{l}\text { Foi realizado questionário para avaliar a } \\
\text { competência dos alunos na aplicação de } \\
\text { um suporte básico de vida. Verificou-se } \\
\text { uma melhoria significativa nos } \\
\text { resultados do questionário aplicado } \\
\text { depois de um treinamento feito pela } \\
\text { equipe que compunha o estudo. A } \\
\text { proporção de estudantes que se sentiam } \\
\text { bem preparados para realizar SBV } \\
\text { aumentou de } 30 \% \text { para } 90 \% \text {. }\end{array}$ \\
\hline $\begin{array}{l}\text { CHENG, Y.H. et. al / } \\
2021\end{array}$ & EUA & $\begin{array}{l}\text { O objetivo deste estudo foi avaliar a } \\
\text { eficácia de um curso introdutório de } \\
\text { primeiros socorros } \\
\text { ressuscitação de } 2,5 \text { horas para } \\
\text { alunos do ensino médio. }\end{array}$ & $\begin{array}{l}\text { Ensaio clínico } \\
\text { randomizado }\end{array}$ & $\begin{array}{l}\text { Poucos estudantes tiveram formação } \\
\text { prévia em primeiros socorros, atitudes } \\
\text { positivas e mais confiança no } \\
\text { desempenho dos primeiros socorros } \\
\text { após a aplicação do curso. }\end{array}$ \\
\hline
\end{tabular}




\begin{tabular}{|c|c|c|c|c|}
\hline $\begin{array}{l}\text { ROSSETTO, A. et. al / } \\
2020\end{array}$ & Austrália & $\begin{array}{l}\text { O objetivo da pesquisa é } \\
\text { demonstrar que os programas de } \\
\text { primeiros socorros inseridos na } \\
\text { escola melhoraram o conhecimento } \\
\text { e as habilidades dos alunos acerca } \\
\text { da temática. }\end{array}$ & $\begin{array}{l}\text { Ensaio clínico } \\
\text { randomizado }\end{array}$ & $\begin{array}{l}\text { Sublinham a necessidade de uma } \\
\text { concepção mais rigorosa de estudos } \\
\text { para estabelecer a eficácia de } \\
\text { programas de primeiros socorros } \\
\text { baseados na escola, irá contribuir para o } \\
\text { desenvolvimento de uma educação para } \\
\text { a saúde envolvente e relevante para os } \\
\text { jovens. }\end{array}$ \\
\hline $\begin{array}{l}\text { REVERUZZI, B. et. al / } \\
2016\end{array}$ & Austrália & $\begin{array}{l}\text { Esta revisão examina a amplitude } \\
\text { do treinamento de primeiros } \\
\text { socorros entregue aos alunos da } \\
\text { escola e os componentes que } \\
\text { são adequados para a idade dos } \\
\text { adolescentes. }\end{array}$ & $\begin{array}{l}\text { Ensaio de } \\
\text { controle } \\
\text { randomizado }\end{array}$ & $\begin{array}{l}\text { Os recursos educativos e a formação de } \\
\text { facilitadores foram considerados como } \\
\text { características comuns de programas } \\
\text { eficazes }\end{array}$ \\
\hline CRUZ, K.B. et. al / 2021 & Costa Rica & $\begin{array}{l}\text { Identificar na literatura quais as } \\
\text { intervenções de educação para a } \\
\text { saúde em primeiros socorros são } \\
\text { utilizadas no contexto escolar. }\end{array}$ & $\begin{array}{l}\text { Estudo } \\
\text { descritivo } \\
\text { com revisão } \\
\text { integrada de } \\
\text { literatura. }\end{array}$ & $\begin{array}{l}\text { Ações de educação de primeiros } \\
\text { socorros para professores, } \\
\text { colaboradores e estudantes. }\end{array}$ \\
\hline $\begin{array}{l}\text { MONTEIRO, M. L. R. B. } \\
\text { P, et. al / } 2020\end{array}$ & Portugal & $\begin{array}{l}\text { Este estudo pretende avaliar o } \\
\text { resultado de uma sessão de treino } \\
\text { em suporte básico de vida no } \\
\text { conhecimento teórico e } \\
\text { autoeficácia, imediatamente e seis } \\
\text { meses após, em população } \\
\text { pediátrica. }\end{array}$ & $\begin{array}{l}\text { Estudo } \\
\text { longitudinal. }\end{array}$ & $\begin{array}{l}\text { Aumento significativo no conhecimento } \\
\text { e autoeficácia nas crianças após este } \\
\text { treino único de primeiros socorros. }\end{array}$ \\
\hline $\begin{array}{l}\text { BARBOSA, H.G.D, et. al } \\
\text { / } 2020\end{array}$ & Brasil & $\begin{array}{l}\text { Este estudo objetiva avaliar a } \\
\text { efetividade do treinamento de } \\
\text { crianças em suporte básico de vida. }\end{array}$ & $\begin{array}{l}\text { Revisão } \\
\text { sistemática da } \\
\text { literatura }\end{array}$ & $\begin{array}{l}\text { Esse estudo demonstrou a maior } \\
\text { eficácia na realização do Suporte } \\
\text { Básico de Vida (SBV) em crianças } \\
\text { maiores. Contudo, foi constatado como } \\
\text { a motivação, maior em crianças } \\
\text { menores, é um fator que se sobressai } \\
\text { diante das diferenças físicas. }\end{array}$ \\
\hline $\begin{array}{l}\text { TAVARES, A. et. al / } \\
2016\end{array}$ & Portugal & $\begin{array}{l}\text { Este estudo objetiva avaliar a } \\
\text { necessidade de formação dos } \\
\text { cidadãos em relação ao suporte } \\
\text { básico de vida (SBV) e } \\
\text { correlacionar com a faixa-etária } \\
\text { ideal para o início desse } \\
\text { conhecimento. }\end{array}$ & $\begin{array}{l}\text { Revisão de } \\
\text { literatura }\end{array}$ & $\begin{array}{l}\text { A inclusão da formação em suporte } \\
\text { básico à vida (SBV) nas escolas é } \\
\text { recomendável e exequível, Nessa lógica } \\
\text { de pensamento, perspectivam-se adultos } \\
\text { capazes e confiantes, com competências } \\
\text { de executar manobras de SBV. }\end{array}$ \\
\hline $\begin{array}{l}\text { TONY, A.C.T. et. al / } \\
2020\end{array}$ & Brasil & $\begin{array}{l}\text { Avaliar o conhecimento de } \\
\text { estudantes do ensino básico antes e } \\
\text { após intervenção educativa sobre } \\
\text { Suporte } \\
\text { Básico de Vida em situação de } \\
\text { parada cardiorrespiratória em } \\
\text { adultos. }\end{array}$ & $\begin{array}{l}\text { Estudo quase- } \\
\text { experimental }\end{array}$ & $\begin{array}{l}\text { A efetividade da intervenção com a } \\
\text { ampliação do conhecimento sobre } \\
\text { Suporte Básico de Vida em parada } \\
\text { cardiorrespiratória, reforça a } \\
\text { importância da Enfermagem nas ações } \\
\text { de educação em saúde nas escolas de } \\
\text { ensino básico. }\end{array}$ \\
\hline DUTRA, B.D. et. al / & Brasil & Validar o conteúdo e a aparência do & Pesquisa & Auxiliar no ensino para crianças em \\
\hline
\end{tabular}




\begin{tabular}{|c|c|c|c|c|}
\hline 2021 & & $\begin{array}{l}\text { jogo educativo sobre primeiros } \\
\text { socorros para crianças em idade } \\
\text { escolar com experts da área da } \\
\text { educação e saúde. }\end{array}$ & $\begin{array}{l}\text { metodológica, } \\
\text { quantitativa/ } \\
\text { descritiva. }\end{array}$ & $\begin{array}{l}\text { idade escolar, pelos profissionais de } \\
\text { saúde e profissionais de educação } \\
\text { infantil como opção às práticas } \\
\text { educativas tradicionais no aprendizado } \\
\text { de primeiros socorros. }\end{array}$ \\
\hline $\begin{array}{l}\text { GOMES, A.L. et. al / } \\
2021\end{array}$ & Brasil & $\begin{array}{l}\text { Avaliar o conhecimento dos } \\
\text { professores de educação infantil } \\
\text { sobre o primeiro auxílio antes e } \\
\text { depois da participação em uma ação } \\
\text { educativa. }\end{array}$ & $\begin{array}{l}\text { Estudo quase- } \\
\text { experimental }\end{array}$ & $\begin{array}{l}\text { Esse estudo demonstrou um aumento } \\
\text { significativo dos resultados no pós-teste } \\
\text { em relação ao pré-teste de } \\
\text { conhecimento de professores acerca dos } \\
\text { primeiros socorros. }\end{array}$ \\
\hline $\begin{array}{l}\text { MOURA, T.V.C. et. al / } \\
2018\end{array}$ & Brasil & $\begin{array}{l}\text { O presente estudo busca relatar a } \\
\text { experiência de atividades de uma } \\
\text { extensão universitária sobre } \\
\text { "Oficinas de primeiros socorros } \\
\text { com estudantes do ensino médio" } \\
\text { desenvolvidas por alunos do curso } \\
\text { de Bacharelado em } \\
\text { Enfermagem. }\end{array}$ & $\begin{array}{l}\text { Estudo de } \\
\text { campo. }\end{array}$ & $\begin{array}{l}\text { Os resultados alcançados foram } \\
\text { significativos, visto que na roda de } \\
\text { conversa a participação dos alunos foi } \\
\text { decisiva para a construção do projeto, } \\
\text { pois houve demonstração de interesse } \\
\text { dos } \\
\text { mesmos em relação aos assuntos } \\
\text { tratados. }\end{array}$ \\
\hline $\begin{array}{l}\text { MATOS, D.O.N. et. al / } \\
2016\end{array}$ & Brasil & $\begin{array}{l}\text { Este trabalho objetiva identificar a } \\
\text { necessidade da disciplina de } \\
\text { primeiros socorros para alunos do } \\
\text { ensino básico, como também } \\
\text { analisar problemas e vantagens da } \\
\text { inclusão. }\end{array}$ & $\begin{array}{l}\text { Estudo } \\
\text { descritivo/exp } \\
\text { loratório } \\
\text { Revisão } \\
\text { bibliográfico }\end{array}$ & $\begin{array}{l}\text { A partir desse estudo podemos notar a } \\
\text { necessidade da implementação do } \\
\text { suporte básico na grade curricular dos } \\
\text { alunos, bem como a capacitação efetiva } \\
\text { dos profissionais que compõem o } \\
\text { ambiente escolar. }\end{array}$ \\
\hline
\end{tabular}

Fonte: Autores.

Conforme os estudos citados foram evidenciados que entre todos os profissionais de saúde, o enfermeiro também possui uma fundamentação teórica, cientifica e prática sobre o suporte básico de vida, mas esse profissional em especial já vem desde a sua graduação atuando no desenvolvimento de ações de educação em saúde voltado para a comunidade. Não obstante, o enfermeiro irá atuar como promotor de saúde dentro do ambiente escolar, por isso se faz necessário a implementação desse profissional nesse espaço, agindo na aplicação de treinamentos, orientações e atuando na prevenção de agravos.

\section{Discussão}

Para Cornacine, et al., 2019 a prática dos primeiros socorros se caracteriza como um atendimento imediato, em casos de acidentes ou mal súbito, visando a manutenção dos sinais vitais e evitando o agravamento da problemática até que o auxílio especializado esteja na cena. Torna-se, uma prática necessária para a sobrevivência da vítima, tal atendimento pode ser realizado pela população, desde que seja capacitada em sua conduta e saiba agir frente a essas situações.

Conforme Santana, 2020 apesar da sua grande relevância, e tendo em vista que os agravos acontecem, na maior parte das vezes durante o cotidiano da população, inferindo-se em domicílio, nas áreas públicas, no ambiente de trabalho e nas escolas, é surpreendente como a população tem um déficit nesse parâmetro.

Vale ressaltar que a saúde e a educação são fatores que estão plenamente associados, dessa forma, é essencial que a educação promova o esclarecimento necessário na promoção em saúde para a população e os professores são potenciais 
testemunhas a esses agravos, como é cita Neto, et al., 2018. Nesse contexto, a escola é um agregador vital, pois, no âmbito escolar o jovem se torna mais suscetível para apreender as técnicas inseridas.

Contudo, em concordância com o estudo de Martin, 2015, que apontou a deficiência que os professores da rede de ensino apresentavam em relação às condutas básicas de primeiros socorros, na qual existe a necessidade de aplicar intervenções de educação em saúde para minimizar esse déficit, assim melhorando a assistência inicial prestada.

Além disso, Silva, 2017 aponta em seu estudo a importância da eficácia das condutas de suporte básico à vida treinando os profissionais da educação na identificação correta do tipo de eventualidade para aplicação da conduta adequada àquele acidente, reduzindo complicações e o risco da vítima evoluir a óbito.

Vale enfatizar que, segundo análise de Silva, 2018 no Brasil, os acidentes são os maiores fatores que causam morte entre crianças e jovens de 1 a 14 anos, e a escola se torna um local propício para esse acontecimento devido à alta exposição do jovem a riscos. Dessa forma o conhecimento de professores em primeiros socorros é vital, sendo capacitados para atuar em situações emergenciais, constituindo um dos primeiros alicerces nessa situação.

Ademais, em concomitância a Brito, 2018 em relação a escolas especializadas para crianças com algum transtorno percebe-se uma maior necessidade de instruir as pessoas que compõem o quadro educacional, pois crianças com alguma deficiência física, cognitivas, auditivas, visuais e múltiplas apresentam-se com maiores riscos a se submeter a acidentes.

Não obstante, Grimaldi, 2020 cita que o conhecimento em primeiros socorros deve ser propagado para os alunos, uma vez que os mesmos podem reconhecer e atuar nesses casos. Ademais, os mesmos se tornam multiplicadores dessas informações tanto na composição familiar, como no ciclo de amizade. Inserir esse conhecimento no meio escolar é, por isso, de grande valia para a estrutura social.

Nessa mesma linha Leite, 2018 referiu que o jovem passa em média 1/3 do seu dia no ambiente escolar, interagindo com outras pessoas em um ambiente que pode ser passível a ocorrência de acidentes. A escola, por sua vez, é responsável pela integridade física dos alunos que estão introduzidos em seu meio. Portanto, para garantia da segurança de seus ingressos é fundamental a compreensão do suporte básico de vida também por parte de alunos.

Em anuência com Boné, 2020 a capacitação dos estudantes é essencial para o desempenho nas condutas frente a um acidente, demonstrado em sua pesquisa que existiu o aumento de $60 \%$ dos estudantes que se sentiam preparados para agir após a intervenção, aplicando as condutas de forma efetiva, existindo uma grande demanda por condutas básicas de SBV.

Com conciliação a pesquisa de Cheng, 2021 que enfatizou que poucos estudantes têm pouca ou nenhuma formação em primeiros socorros, assim não sabendo agir diante um eventual incidente, com isso existiu uma maior autonomia e confiança nas condutas dos estudantes após a aplicação do treinamento com condutas adequadas, fazendo válida a importância de se aplicar cursos de capacitação em primeiros socorros no ambiente escolar.

Seguindo a linha dos estudos de Rossetto, 2020; REVERUZZI, 2016 que retrata a importância da qualidade e eficácia de treinamentos de primeiros com o uso de recursos pedagógicos atualizados para facilitar o aprendizado do reconhecimento do tipo de acidente para definir e aplicar a melhor conduta para aquela respectiva eventualidade, desenvolvendo uma educação em saúde que treine a população com condutas apropriadas atualizadas e com embasamento teórico-prático científico.

Nesse contexto, foi promulgada em 2018 a Lei Lucas, nome dado à lei 13.722 após um incidente envolvendo uma criança, no qual, cita Cruz, 2021 essa lei determinou que funcionários e professores de escolas de educação infantil e básica, particulares e públicas, bem como qualquer ambiente de recreação infantil devem ter conhecimento sobre suporte básico de vida.

Similarmente a essa situação, Monteiro, 2020 ressalta que um dos mais graves problemas de saúde pública é a parada cardiorrespiratória (PCR), com o agravante de mortalidade que acomete em escala global. Mesmo com os avanços científicos 
na prevenção de tal problema, uma vez que a PCR ocorre à reanimação cardiopulmonar (RCP), realizada de forma precoce e eficaz, se torna o mais importante preditor de sobrevida para essa vítima (Barbosa, et. al, 2020).

A reanimação cardiopulmonar (RCP), trata-se da manutenção da circulação cardiovascular e da respiração de suporte com o objetivo de preservar a sobrevida da vítima. Essa é a primeira atitude a ser tomada, tanto no ambiente intra-hospitalar como no pré-hospitalar, para reverter a parada cardiorrespiratória como é enfatizado no estudo de Tavares, et. al, 2016.

É importante frisar que toda essa ação pode ser desenvolvida por um público leigo, desde que esteja capacitado para tal. Em razão disso Tony, 2020 relatou uma pesquisa realizada por estudantes de enfermagem que demonstrou uma ineficiência em relação às práticas no Suporte Básico de Vida em alunos do ensino básico em um pré-teste realizado. Após um treinamento teórico-prático o conhecimento desses estudantes teve um importante acréscimo, pôde-se assim demonstrar a eficiência na capacitação de um público leigo.

Em consonância a Dutra, 2021, o enfermeiro detém um importante papel na construção educativa em saúde para a população, uma vez que possui prática em atividades e programas educativos, como o programa Saúde na Escola, versando sobre a promoção da saúde do escolar. De acordo com seu exercício profissional, a prática da educação em saúde, com vistas ao aumento do conhecimento populacional é de sua proposição (Gomes, et. al, 2021). Fomenta-se, assim, o avanço da saúde do indivíduo e da sociedade em geral.

Para tal, diversas metodologias podem ser utilizadas, conforme demonstra Moura, 2018, em uma prática extensionista com alunos do ensino médio de duas escolas públicas que utilizou como metodologia a roda de conversa e jogos o que favoreceu a concentração e compreensão dos alunos. Com essa prática foi possível evidenciar o entendimento dos alunos acerca da temática.

Desse modo, segundo Matos, 2016 fomenta-se que a formação em primeiros socorros, desde os primeiros anos da escola na educação básica, é vital para influenciar a ação correta frente a uma situação de risco, diminuindo os riscos de sequelas e óbitos em casos de acidente ou mal súbito. Infere-se, assim, a importância do conhecimento das técnicas e ações mais apropriadas para os primeiros socorros.

\section{Conclusão}

Após a análise de todos os fatores que compõem esses estudos, demostram que a presença de um profissional de saúde, em particular o enfermeiro dentro do ambiente escolar como educador e promotor de saúde torna-se essencial, desmistificando a visão que o profissional só está para atuar no processo saúde-doença e o tornando o protagonista na prevenção de agravos e na promoção à saúde dentro das escolas, seja no treinamento de primeiros socorros, como também incentivando atos saudáveis e condutas corretas, motivando o aumento na qualidade da assistência inicial prestada durante um acidente, bem como minimizando os possíveis riscos a saúde do indivíduo.

A escola por sua vez, é responsável pela formação e construção dos cidadãos que formam a sociedade, com isso fazse necessário à migração desses profissionais para o ambiente escolar para prevenir, orientar e treinar quanto aos cuidados de saúde e suporte básico a vida, para que quando a criança tenha chegado a sua fase adulta consiga desempenhar condutas adequadas e com qualidade durante um eventual acidente que expor a risco o bem estar físico do indivíduo acometido, além de atuar de forma eficiente como multiplicadores de conhecimento.

Por meio de educação em saúde e intervenções educativas, acredita-se que a introdução de um plano de treinamento de suporte básico de vida dentro do ambiente escolar, aderindo país, colaboradores e alunos, irá influenciar positivamente na migração da cultura curativista predominante em nosso país, para uma cultura mais preventiva. 
Research, Society and Development, v. 11, n. 1, e22711124739, 2022

(CC BY 4.0) | ISSN 2525-3409 | DOI: http://dx.doi.org/10.33448/rsd-v11i1.24739

\section{Referências}

Alba Martin, R. (2015). Educación para la salud en primeros auxilios dirigida al personal docente del ámbito escolar. Enfermagem Universitária, 12(2), 88-92. http://www.scielo.org.mx/scielo.php?script=sci_arttext\&pid=S1665-70632015000200088\&lng=es\&nrm=iso.

Amaral, V. Messias, M. \& Nascimento, L. (2014). O enfermeiro promovendo saúde como educador escolar: atuando em primeiros socorros. (6) | ISSN 21758255 | Revista Transformar-centro universitário São José de Itaperuna.

Bakke H. K., Schwebs, R. (2017). First-aid training in school: amount, content and hindrances. Acta Anaesthesiol Scand, 61(10):1361-1370. doi: 10.1111/aas.12958. Epub 2017 Aug 17. PMID: 28832913; PMCID: PMC5659131.

Barbosa, H. G. D. et al. (2020). Avaliação do impacto e efetividade do treinamento de crianças em suporte básico de vida: uma revisão sistemática. Rev Med (São Paulo). 99(1): 56-61.

Boné, M. et. al. (2020). Suporte básico de vida na escola: o relato da evidência. Revista Holos, 36(6), 1807-1600. DOI: 10.15628/holos.2020.8959

Brasil. (2018). Presidência da República (BR). Subchefia para Assuntos Jurídicos. Lei nº 13.722, de 4 de outubro de 2018: torna obrigatória a capacitação em noções básicas de primeiros socorros de professores e funcionários de estabelecimentos de ensino públicos e privados de educação básica e de estabelecimentos de recreação infantil. http://www.planalto.gov.br/ccivil_03/_ato2015-2018/2018/lei/L13722.htm.

Brito, J. G. et al. (2020). Efeito de capacitação sobre primeiros socorros em acidentes para equipes de escolas de ensino especializado. Revista Brasileira de Enfermagem, 73(2):e20180288.

Cheng, Y. H. et al. (2021). Non-resuscitative first aid training and assessment for junior secondary school students. Medicine, 100(34).

Cornacine, A. C. et. al. (2019). Atendimento emergencial: a importância de treinamento tanto aos profissionais de saúde quanto a população. Revista Saúde em Foco, $\mathrm{n}^{\circ} 11$.

Cruz, K. B. et al. (2021). Intervenciones de educación en salud en primeros auxilios en el entorno escolar: una revisión integradora. Revista Enfermería Actual, 2511-4775.

Dutra, B. D., et al. (2021). Validation of an educational game about first aid for schoolchildren. Revista Brasileira de Enfermagem, 74(6):e20201107.

Leite, H. S. N. et al. (2018). Primeiros socorros na escola: conhecimento da equipe que compõe a gestão educacional. Temas em Saúde Ed. especial, ISSN 244-2131

Lima, L. L. N.; Junior, R. N. (2016.). Brigada estudantil de prevenção de acidentes e primeiros socorros em palmas (TO). Revista Brasileira de Educação Médica. 40(2).

Matos, D.O.N. et al. (2016). Inclusão da disciplina de primeiros socorros para alunos do ensino básico. Revista Interdisciplinar, 9(3), $168-178$.

Mendes, K. D. S.; Silveira, R. C. C. P.; Galvâo, C. M. (2008). Revisão integrativa: método de pesquisa para a incorporação de evidências na saúde e na Enfermagem. Texto \& Contexto Enfermagem, 17(4),758-764.

Monteiro, M. L. R. B. P, et. al. (2020). Avaliação de conhecimentos e da autoeficácia antes e após ensino de suporte básico de vida a crianças. Rev. Paul Pediatr, 39:e 2019143.

Moura, T. V. C. et al. (2018). Práticas educativas em primeiros socorros: relato de experiência extensionista. Revista Ciência e Extensão, 14(2), 180-187.

Neto, N. M. G. et al. (2018), Vivências de professores acerca dos primeiros socorros na escola. Revista Brasileira de Enfermagem. 71(4): 1775-82.

Ordem dos enfermeiros, (2019). Regulamento do exercício profissional do enfermeiro. Decreto-Lei n. ${ }^{\circ}$ 161/96, de 4 de Setembro.

https://www.ordemenfermeiros.pt/arquivo/AEnfermagem/Documents/REPE.pdf.

Reveruzzi, B., Buckley, L., Sheehan, M. (2016). School-Based First Aid Training Programs: A Systematic Review. J Sch Health, 86(4), 266-72. doi: 10.1111/josh.12373. PMID: 26930238.

Rossetto, A., Morgan, A. J., Hart, L. M., Kelly, C. M., Jorm, A. F. (2020). Frequency and quality of first aid offered by older adolescents: a cluster randomised crossover trial of school-based first aid courses. PeerJ, 8:e9782. DOI 10.7717/peerj.9782.

Rovisco, M. L. et al. (2021). Avaliação de conhecimentos e da autoeficácia antes e após ensino de suporte básico de vida a crianças. Rev Paul Pediatr, 39:e2019143

Santana, M. M. R. et al. (2020). Intervenção educativa em primeiros socorros para escolares da educação básica. Revista de Enfermagem. UFSM. 10(70), 1-17. Silva, D. P. et al. (2018). Primeiros socorros: objeto de educação em saúde para professores. Revista de Enfermagem UFPE on-line, 12 (5):1444-53.

Silva, L et al. (2017). Primeiros socorros e prevenção de acidentes no ambiente escolar: intervenção em unidade de ensino. Revista Enfermagem em Foco, 8(3): 25-29.

Sociedade de Pediatria de São Paulo. Boletim da sociedade de pediatria de São Paulo. Ano 2, no 6, nov/2017. https://www.spsp.org.br/2017/11/13/novembroprateado/.

Tavares, A. et al. (2016). Ausência de formação em suporte básico de vida pelo cidadão: um problema de saúde pública? Qual a idade certa para iniciar? Revista Portuguesa de saúde pública, 34(1):101-104.

Tony A.C.C. et al. (2020). Teaching basic life support to schoolchildren: quasi-experimental study. Revista Latino-Americana de Enfermagem, 28:e3340. 